\title{
Trajetórias assistenciais de usuárias pela APS em uma regiấo de saúde: trânsito livre, pontos de lentidão e parada
}

\author{
I ${ }^{1}$ Jôse Ribas Galvão, ${ }^{2}$ Patty Fidelis de Almeida, ${ }^{3}$ Adriano Maia dos Santos, \\ ${ }^{4}$ Noêmia Fernanda Santos Fernandes I
}

Resumo: $\mathrm{O}$ artigo objetiva avaliar o acesso e a organização das ações da Atenção Primária à Saúde (APS) utilizando o câncer do colo do útero (CCU) como evento traçador. Foram construídas trajetórias assistenciais de mulheres com diagnóstico de lesão de alto grau do colo uterino, adscritas a Unidades Básicas de Saúde Tradicionais e Unidades de Saúde da Família, de zonas urbana e rural, em municípios do interior e na sede de uma região de saúde da Bahia. As mulheres indicam dificuldade de acesso às consultas médicas na APS, sobretudo na zona rural. Além dos obstáculos para agendamento do citopatológico, a maioria relata náo receber convocação para sua realizaçâo e não participar de atividades educativas sobre o tema. As açōes de controle do CCU na APS são restritas à realização do citopatológico, avaliação do resultado e encaminhamento para rede especializada, sem seguimento do cuidado e com falhas na comunicação profissionalusuária. Foram identificadas barreiras no acesso à APS, em geral, e para controle do CCU relacionadas ao escopo de açôes, principalmente nas unidades localizadas no município com menor disponibilidade de serviços, na zona rural e nas UBS tradicionais.

> Palavras-chave: Atenção Primária à Saúde; assistência integral à saúde; neoplasias do colo do útero.

\author{
1 Instituto Multidisciplinar em \\ Saúde, Universidade Federal da \\ Bahia. Vitória da Conquista-BA, \\ Brasil (jorigal@hotmail.com). \\ ORCID: 0000-0003-4131-1393. \\ ${ }^{2}$ Universidade Federal \\ Fluminense. Niterói-RJ, Brasil \\ (pattyfidelis@id.uff.br). \\ ORCID: 0000-0003-1676-3574. \\ ${ }^{3}$ Instituto Multidisciplinar em \\ Saúde, Universidade Federal da \\ Bahia. Vitória da Conquista-BA, \\ Brasil (maiaufba@ufba.br). \\ ORCID: 0000-0001-9718-1562. \\ ${ }^{4}$ Instituto Multidisciplinar em \\ Saúde, Universidade Federal da \\ Bahia. Vitória da Conquista-BA, \\ Brasil (ftanoemiafsf@gmail.com). \\ ORCID: 0000-0002-0713-949X.
}

Recebido em: 21/01/2019 Revisado em: 06/05/2019 Aprovado em: 25/05/2019 


\section{Introdução}

Diversos fatores reforçam a necessidade de medidas que promovam a integração dos serviços e açóes de saúde, dentre eles, o envelhecimento populacional e a prevalência de agravos crônicos (BOERMA, 2010). No Brasil, a Atenção Primária à Saúde (APS) é considerada estratégica na reorganização do sistema de saúde para alcance de atenção integral e integrada. Embora apresente resultados positivos ao longo de sua implementação (AQUINO; OLIVEIRA; BARRETO, 2009; DOURADO et al., 2011; MALTA et al., 2016), enfrenta dificuldades para ocupar a centralidade e coordenação no Sistema Único de Saúde (SUS), assumindo, muitas vezes, uma posição periférica em uma rede de atenção desarticulada (SANTOS; GIOVANELLA; 2016). As mesmas dificuldades são observadas em relação às doenças crônicas, em geral, e, no caso do câncer do colo do útero (CCU), além da fragmentação (OLIVEIRA et al., 2010), dificuldades no acesso ao citopatológico (BRITO-SILVA, 2014), estrutura física e processo de trabalho na APS (TOMASI et al., 2015).

O CCU é o quarto tipo de câncer mais comum em mulheres no mundo, atingindo a terceira posição no Brasil e, em regiōes de menor desenvolvimento socioeconômico, como o Nordeste do país, é o segundo mais incidente (INCA, 2017). De 1995 a 2015, foi observado aumento da mortalidade no Norte e Nordeste (INCA, 2018) e diminuição nas demais regiōes, o que evidencia forte gradiente de desigualdade na determinação social deste agravo (GIRIANELLI; GAMARRA; AZEVEDO E SILVA, 2014). Sua relevância social e como problema de saúde pública justificam investimentos na organização e acesso aos serviços para a detecção precoce por meio do rastreamento e tratamento das lesóes precursoras, principalmente para mulheres com maior vulnerabilidade (RODRIGUES; BUSTAMANTE-TEIXEIRA, 2011).

Para o controle do câncer do colo uterino (CCCU), deve ser garantido acesso humanizado e integral às açôes e serviços de promoção da saúde, detecção precoce, tratamento adequado e em tempo oportuno. Nesse contexto, uma APS qualificada, organizada, resolutiva e integrada aos demais níveis de atenção desenvolve papel essencial. Todavia, conformar a APS como porta de entrada preferencial, coordenadora e integradora da rede de serviços é um desafio e este papel parece não ter sido efetivado em sua completude (CECÍLIO et al., 2012).

Esforços são prementes para a melhoria da qualidade dos serviços prestados pela APS, tanto na esfera micro, por meio da organização do processo de trabalho 
das equipes, quanto por investimentos mais abrangentes, como a consolidação da função de coordenação do cuidado, possibilitando a integralidade e respostas às necessidades de saúde da população (ARANTES; SHIMIZU; MERCHANHAMANN, 2016). Reconhecida sua importância no controle do CCU, este evento é utilizado como traçador, com o objetivo de avaliar o acesso e a organização das açôes desenvolvidas pela APS na perspectiva das usuárias, tendo como cenário uma região de saúde. Parte-se do princípio de que o fortalecimento da APS é a base primeira para viabilizar a coordenação e a oferta de cuidados integrais e integrados no SUS (ALMEIDA; FAUSTO; GIOVANELLA, 2011).

\section{Método}

Trata-se de estudo avaliativo, com abordagem qualitativa, que atribuiu centralidade à percepção das usuárias (PINHEIRO; SILVA JÚNIOR, 2011). Foi utilizada a abordagem das Trajetórias Assistenciais (TA), metodologia que tem evidenciado aspectos do processo de trabalho, organização, funcionamento da rede e qualidade do cuidado perante as necessidades percebidas pelos usuários (SILVA et al., 2011). As TA não apresentam a mesma amplitude dos itinerários terapêuticos, pois trata do percurso pelos serviços disponíveis nas redes assistenciais formais (GERHARDT; BURRILLE; MÜLLER, 2016).

A utilização de traçadores possibilita a avaliação da qualidade do cuidado, de fatores relacionados à integração da rede, além de evidenciar as demandas dos usuários (TANAKA; ESPÍRITO-SANTO, 2008). A condição eleita para a construção das TA foi o câncer do colo uterino, por sua relevância social e possibilidade de detecção e tratamento oportuno das lesôes precursoras, mais especificamente, da lesão intraepitelial escamosa de alto grau (HSIL). Tais lesôes demandam cuidados de outros níveis, sendo sua análise reveladora do grau de articulação da rede de atençâo à saúde (SILVA et al., 2016). Outrossim, a APS representa imprescindível ponto de atenção e deve desenvolver ações de CCCU que envolvam promoção, prevenção, detecção precoce e cuidados paliativos; rastreamento organizado pelo exame citopatológico; busca ativa de mulheres com resultado alterado; encaminhamento para AE quando necessário e acompanhamento durante e após o tratamento (BRASIL, 2013).

Este estudo envolveu uma Regiáo de Saúde, na Bahia, composta por 19 municípios caracterizados na tabela 1 . Essa regiáo tem uma população de 637.414 habitantes 
e 32,5\% residem em zona rural (BAHIA, 2012). A maior parte dos municípios concentra-se no estrato de 10.000 a 25.000 habitantes e apenas três situam-se na faixa de desenvolvimento humano médio. $\mathrm{Na}$ sede está praticamente toda a oferta de atenção especializada e hospitalar da regiáo de saúde.

Foram selecionados três municípios (identificados por letras): município A por ser o maior, sede da regiáo, ter maior disponibilidade de serviços, menor cobertura de ESF e maior dispersão territorial da área rural; município B, por ser de médio porte e ter menos recursos assistenciais para atender as usuárias com HSIL (comparado ao município C), dependendo da sede para exames de confirmação diagnóstica e tratamento; e município $\mathrm{C}$, o de menor porte dentre os três, por ter maior oferta de serviços de confirmação diagnóstica, dentre os municípios do interior da região, apesar de depender da sede para realização do anatomopatológico do colo uterino e tratamento das mulheres com HSIL. O objetivo foi selecionar municípios de diferentes características em relação à dependência dos fluxos regionais, para avaliar trajetórias e seus possíveis obstáculos para organização da APS e seguimento do cuidado ao CCU.

Os municípios selecionados apresentam cobertura populacional de Agente Comunitário de Saúde (ACS) e por Equipe de Saúde da Família (EqSF) de 100\%, exceto o município A. O município sede possui ampla zona rural, com 284 povoados e 12 distritos. Onde há cobertura pela ESF, a equipe é responsável por uma área de abrangência com povoados dispersos e oferta de açóes e serviços em esquema de rodízio. Em alguns, os usuários precisam se dirigir a outro povoado da área de abrangência. 


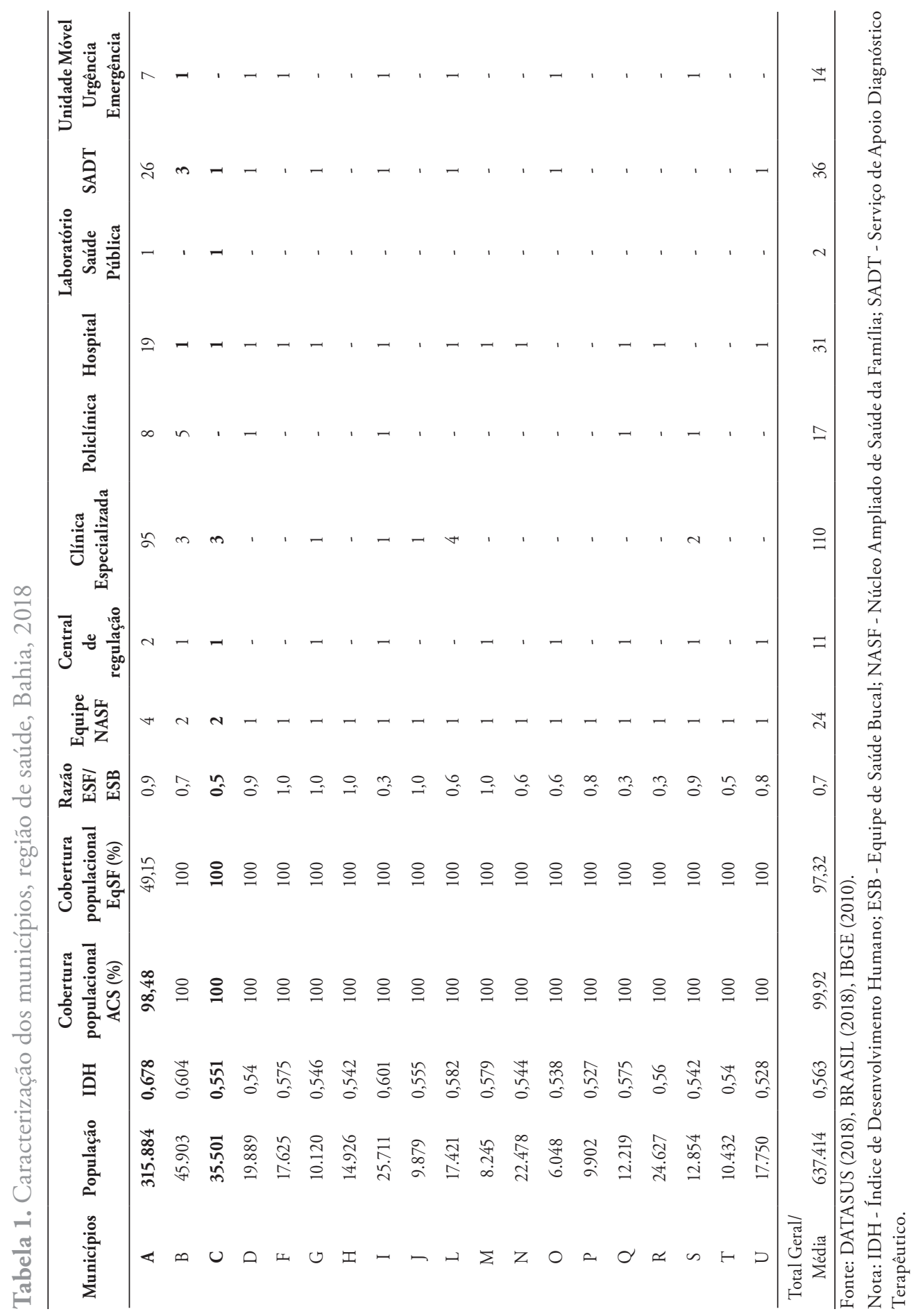


Para construção das TA, foram selecionadas mulheres com diagnóstico de lesão intraepitelial escamosa de alto grau do colo uterino em 2016, entrevistadas no $2^{\circ}$ semestre de 2017, a partir da relação do Sistema de Informação do Câncer (SISCAN), exceto no município A, onde foram consultados os registros de livro do Laboratório Municipal de Citopatologia. Identificou-se 86 usuárias no município A, 11 no município C e 4 no município B. Posteriormente, foi verificada a distribuição das mulheres conforme modalidade de APS, área urbana ou rural e município de moradia. Foram construídas 26 trajetórias assistenciais.

A seleção ocorreu ao interior de cada modalidade de APS, por meio de sorteio, e em seguida, as mulheres foram convidadas a participar da entrevista com apoio da equipe de APS, até completar um conjunto de informaçóes por saturação de conteúdo. Foram entrevistadas todas as mulheres do município B, de zona rural do município C e de Unidade Básica de Saúde (UBS) tradicional rural do município A, devido ao pequeno número, conforme tabela 2 .

Tabela 2. Número de entrevistas realizadas por município e modalidade de APS, Bahia, 2018

\begin{tabular}{lccc}
\hline \multirow{2}{*}{ Município } & Modalidade de APS & $\begin{array}{c}\text { Número de usuárias } \\
\text { identificadas }\end{array}$ & $\begin{array}{c}\text { Número de usuárias } \\
\text { entrevistadas }\end{array}$ \\
\hline \multirow{2}{*}{ Município C } & USF zona rural & 03 & 03 \\
\cline { 2 - 4 } Município B & USF zona urbana & 08 & 04 \\
\hline \multirow{2}{*}{ Município A } & UBS zona urbana & 04 & 04 \\
\cline { 2 - 4 } & UBS zona urbana & 19 & 02 \\
\cline { 2 - 4 } & USF zona rural & 16 & 05 \\
\cline { 2 - 4 } & USF zona urbana & 49 & 04 \\
\hline
\end{tabular}

Fonte: construção própria, a partir dos dados da pesquisa. 
As TA foram construídas a partir de entrevistas em profundidade e complementadas com consulta aos prontuários na APS, além da análise de resultados de exames, procedimentos e relatórios disponibilizados pelas usuárias. A análise de conteúdo foi realizada a partir de categorias predefinidas, elaboradas com base em outros estudos (ALMEIDA; FAUSTO; GIOVANELLA, 2011; ALMEIDA; SANTOS, 2016; MCDONALD et al., 2014), que envolvem componentes para o fortalecimento da função coordenadora da APS, como: acesso e organização da porta de entrada, abrangência e resolubilidade, plano de cuidado, integração horizontal e comunicação entre profissionais. Parte-se da premissa de que somente uma APS fortalecida em seus atributos essenciais seria capaz de assumir também a coordenação do cuidado ao longo da rede de atençáo à saúde, garantindo a longitudinalidade do cuidado para além das fronteiras municipais. Foram analisados aspectos do acesso à APS em geral, mas para maior aproximação à experiência concreta das usuárias, utilizou-se os eventos relacionados à condição traçadora.

Este estudo foi aprovado pelo Comitê de Ética em Pesquisa da UFF (Parecer 2.207.909). As usuárias foram identificadas por números, modalidade de APS (Saúde da Família - SF e UBS tradicional - UBS), localidade de residência (zona urbana - U ou rural - R) e por município de origem (A, B, C): E1SFUA. Todos os nomes mencionados pelas usuárias são fictícios.

\section{Resultados}

A maior parte das entrevistadas tinha entre 25 e 44 anos, a maioria se autodeclarou parda, analfabeta ou com fundamental incompleto, sem ocupação remunerada, rendimento mensal familiar de até 1 salário mínimo e recebimento de algum benefício social, sendo Bolsa Família o mais citado (tabela 3). 
Tabela 3. Características socioeconômicas das entrevistadas, municípios de uma região de saúde, Bahia, 2017

\begin{tabular}{|c|c|c|}
\hline Características & $\mathbf{N}$ & $\%$ \\
\hline \multicolumn{3}{|l|}{ Idade } \\
\hline$<25$ & 01 & 3,8 \\
\hline $25-44$ & 15 & 57,8 \\
\hline $45-64$ & 09 & 34,6 \\
\hline 65 & 01 & 3,8 \\
\hline \multicolumn{3}{|l|}{ Cor autorreferida } \\
\hline Branca & 07 & 26,9 \\
\hline Parda & 12 & 46,2 \\
\hline Preta & 07 & 26,9 \\
\hline \multicolumn{3}{|l|}{ Nível educacional } \\
\hline Analfabetismo & 10 & 38,5 \\
\hline Fundamental incompleto & 11 & 42,3 \\
\hline Fundamental completo & 01 & 3,8 \\
\hline Médio incompleto & 03 & 11,6 \\
\hline Médio completo & 01 & 3,8 \\
\hline \multicolumn{3}{|l|}{ Ocupação remunerada } \\
\hline Sim & 09 & 34,6 \\
\hline Não & 17 & 65,4 \\
\hline \multicolumn{3}{|c|}{ Rendimento mensal do lar (salário mínimo) } \\
\hline Até 1 & 16 & 61,5 \\
\hline Até 2 & 06 & 23,1 \\
\hline Até 3 & 03 & 11,6 \\
\hline Não informou & 01 & 3,8 \\
\hline \multicolumn{3}{|l|}{ Benefício social } \\
\hline Sim & 22 & 84,6 \\
\hline Não & 04 & 15,4 \\
\hline
\end{tabular}

Fonte: construção própria, a partir das entrevistas. 
A seguir, são analisados os principais achados das entrevistas, prontuários e documentação em saúde utilizados na construção das TA. Os elementos para uma APS forte, já mencionados, são apresentados ao longo de categorias que agregam todos os pontos de contato das usuárias com a APS no transcurso das respectivas trajetórias assistenciais.

\section{Busca pelo cuidado na APS}

Os resultados mostram que as usuárias utilizaram a APS como serviço de busca regular para açôes preventivas e assistenciais, como consultas médica, odontológica, de enfermagem e com profissionais do NASF, planejamento familiar, aferição de pressão arterial, glicemia capilar, dispensação de medicamentos, atividades educativas coletivas, visita domiciliar e coleta de exame citopatológico do colo uterino.

Ainda que a busca pela APS tenha sido reportada, foi identificada dificuldade no acesso aos serviços, sobretudo para as consultas médicas. Usuárias da zona urbana dos três municípios e da zona rural do município $\mathrm{C}$ referiram que para marcação de consultas é necessário enfrentar filas na unidade, geralmente no turno matutino, a partir das 5 horas. A depender da quantidade de pessoas e do número de vagas, retornavam sem o agendamento desejado:

[...] praticamente tem que dormir na porta do posto. [...] quando você sai de casa mais ou menos seis horas, a fila já tá enorme. Já vai, volta sem ficha. Tá ruim mais por causa disso [...] tem que acordar de madrugada pra ficar lá no posto, lá no frio, né. Do jeito que tá a malandragem! (E7UBSUA).

A situação é mais grave para mulheres de Unidade de Saúde da Família (USF) rural do município $\mathrm{A}$. As equipes ofertavam açôes e serviços a cada povoado da área, em geral, mensalmente. A marcaçáo de consultas normalmente era intermediada pelo ACS, que informava a data em que os profissionais se encontrariam no povoado. Conforme relato de uma usuária, no dia de atendimento a permanência da equipe era curta, com probabilidade da consulta não ser garantida, seja por falta de vagas ou ausência do profissional:

Bom, eu acho assim, que pela demora que eles demora pra vim, eles tinha que vim pra ficar o dia todo e atender todo mundo assim, conforme cada um tá precisando né? [...] a maioria das vezes eles marca que vem e não vem. E quando vem não atende todo mundo, entáo eu acho constrangedor porque a gente demora de receber o atendimento e quando recebe praticamente não recebe porque né, não chega a até os nossos problemas (E16SFRA). 
Algumas usuárias de zona rural do município A reportaram necessidade de deslocamento com gastos próprios a outro povoado, onde se encontra a unidade sede da área de abrangência ou à unidade de referência em área urbana (UBS tradicional), localizada há mais de 1 hora de suas moradias. Em casos de urgência, as mulheres do meio rural recorrem a medicamentos caseiros e/ou precisam se deslocar à zona urbana, até mesmo de outro município (por ser mais próximo), por meio de frete de carros de vizinhos, o que resulta em altos custos.

A maioria das usuárias dos três municípios apontaram situaçôes não atendidas, que, em sua percepção, poderiam ser acolhidas e/ou resolvidas na APS, resultando em peregrinação entre hospitais, UPA e UBS. A baixa resolutividade da APS foi mais referida por mulheres de zona urbana que da rural e esteve mais presente no discurso das usuárias do município C, que é o de menor porte. Para a maioria das entrevistadas, dos três municípios, este problema foi atrelado ao acesso à Atenção Especializada (AE). Afirmaram não conseguir solucionar seus problemas na UBS, por conta da dificuldade extrema para agendamento de consultas e exames especializados e também por obstáculos no acesso à própria APS.

Segundo as usuárias, não há regularidade no abastecimento de medicamentos, o que gera gastos adicionais. Algumas unidades urbanas no município A não realizam dispensação de medicamentos e em outras do C fica restrita a anti-hipertensivos, hipoglicemiantes e anticoncepcionais. Para essas usuárias, a dispensação está centralizada em farmácias municipais de referência.

Foi referida rotatividade de profissionais nas equipes de APS nos três municípios, tanto em área rural, quanto urbana, sobretudo médicos. Vale ressaltar a substituição de profissionais das diversas categorias, nos municípios B e C, após mudança da gestão municipal em 2017.

O atendimento prestado pela APS, em geral, foi avaliado positivamente pela maioria das mulheres. No município A, ao comparar relatos das residentes de áreas rural e urbana, avaliaçôes negativas estão mais presentes no primeiro grupo. No município C (o menor), as usuárias de zona rural consideraram-se mais satisfeitas se comparadas às da urbana. Neste município, as usuárias eram de áreas rurais menos dispersas que no município A. As mulheres do município B dividiram-se entre avaliaçóes positivas e negativas. Ainda que tenham avaliado positivamente a experiência de uso da APS, muitas falas apontaram fragilidades. As avaliaçôes positivas vincularam-se ao acolhimento, diálogo dos profissionais e à representação 
da unidade como lócus disponível e indispensável de busca de cuidados: "É porque a gente precisa do posto né? E num é só por esse problema né? Que eu tô sentindo. E nós mora aqui, é difícil ir pra cidade [zona urbana do município A]" (E19SFRA).

Foi relatada insatisfação quanto ao atendimento médico, principalmente de UBS tradicionais, associadas à não realização de exame físico e falta de acolhimento. Houve avaliação favorável quanto ao cuidado ofertado por médicos estrangeiros do Programa Mais Médicos, por entrevistadas pertencentes à USF dos municípios A (sede) e C (menor), no que concerne ao vínculo, atenção disponibilizada e comprometimento com a usuária: "Então ela me via, então ela me perguntava [...] Aquela médica é muito diferente da maioria dos outros profissionais aqui do Brasil. Ela tinha um vínculo assim com as pessoas que ela cuidava. Eu gostava muito disso" (E13SFUA).

\section{A APS nas açóes de Controle do Câncer do Colo do Útero}

Em todos os casos, as equipes de APS desenvolveram açóes de controle do CCU, ora mais abrangentes, ora mais restritas (quadro 1). Metade das mulheres referiram não ter participado de atividade educativa sobre o CCU, que quando ocorreu, foi irregular. No município C houve maior participação e no B (o de menor disponibilidade de serviços), nenhuma. No município sede, na zona rural, praticamente não foi relatada qualquer ação educativa e nas UBS tradicionais, geralmente realizadas por estagiários discentes. Meios de comunicação (televisão, rádio e internet), conhecidos e familiares foram mencionados como fontes de informação sobre o CCU.

Das vinte e seis entrevistadas, doze reconheceram a importância do citopatológico para a prevenção do CCU. As demais o relacionavam à detecção ou prevenção de corrimentos, inflamaçóes e doenças na genitália. As mulheres que o associavam a doenças no útero, quando perguntadas, não souberam especificar. Houve duas usuárias que informaram a finalidade de detecção de NIC (Neoplasia Intraepitelial Cervical), entretanto, não conheciam o significado desta sigla e não associavam ao CCU.

$\mathrm{Na}$ maior parte das trajetórias não houve convocação para realização do citopatológico pela equipe de APS, ponto de interdição visualizado no quadro 1. As usuárias realizaram o exame por iniciativa própria ou incentivo de familiares (em menor número):

Aí, a gente que se interessa por a gente mesmo né? Pega e vai. Entendeu? [...] Elas num fala nada não. Se você num procura, você num faz não. É por a gente mesmo. Se, no caso, eu vejo que eu tô precisando, eu vou atrás (E26SFUC). 
Também houve relato recorrente de busca do exame por apresentação de sinais e sintomas como corrimentos, dor pélvica, dispareunia e sangramento após relação sexual. Outrossim, foram verificados casos de baixa adesão ao rastreamento por início tardio (entre 38 e 56 anos), apresentando lesão de alto grau no primeiro resultado (dois no município $\mathrm{C}$ e um no município $\mathrm{B}$ ), e por periodicidade longa entre as coletas, mais de três anos (um no município $\mathrm{C}$ e três no município A). Em ambas situações não houve busca ativa pela equipe de APS para realização do citopatológico.

Contudo, vale ressaltar os raros casos de iniciativas de convocação para realização do exame nos municípios A (sede) e C (menor porte), todas em USF:

Eu comecei fazer agora depois de velha. Eu não fiz nova, mais nova não. Porque não tinha ninguém que falava pra fazer. Aí, depois que começou aqui, que começou mandar fazer. O posto aqui. Aí o posto começou falar comigo pra fazer. Também num ligava não. [...] Ah, porque... Sei lá... Ninguém me chamava. Eu nem sabia o que é isso, nem sabia (E21SFRC).

A maior parte das trajetórias evidenciou alguma barreira no acesso ao exame citopatológico do colo uterino, mais acentuada na zona rural do município A e urbana do C, município de menor porte. Para as entrevistadas deste primeiro grupo, o procedimento não ficava disponível com frequência, devido às características de organização do atendimento, e o tempo de espera para realização podia chegar a três meses. Usuárias do município $\mathrm{C}$ relataram escassez de vagas para o exame e exigência de solicitação do médico ou enfermeiro da própria equipe para marcação do citopatológico na UBS. Metade das entrevistadas do município B enfrentaram dificuldades no agendamento do exame. Somente algumas entrevistadas, todas da sede da região, afirmaram que o procedimento era garantido sem dificuldades, apesar de ser realizado em dia específico.

As coletas do citopatológico foram realizadas predominantemente por enfermeiros. A maior parte das usuárias relatou vergonha, mas referiram que os profissionais acolhem bem, as deixando à vontade. Os casos de citopatológico feito por médicos foram em UBS tradicionais, que contavam com ginecologistas (quatro casos). Houve insatisfação relatada por usuária devido à falta de acolhimento, anamnese e diálogo da ginecologista:

Ela só pergunta o nome e manda deitar. Não fala mais nada com a gente. Não faz aquelas pergunta que tem que fazer. Aí manda deitar e faz. Pronto, tirou o líquido ali, pronto. [...] Não fala mais nada. Entendeu? Essa parte que eu num gosto (E9UBSRA). 
Também foi apontado constrangimento, por mulheres do município A, pela presença de estagiários na coleta.

O tempo de espera para resultado do citopatológico variou de 8 dias a 6 meses, conforme registro em prontuário e relato das entrevistadas. As usuárias que demoraram mais tempo para acesso ao resultado foram as do município $\mathrm{B}$ (25 dias a 6 meses) e os menores, do A (8 dias a 3 meses). Dentre as residentes no município sede, as de UBS tradicional esperaram mais tempo. A busca de mulheres com resultado alterado foi realizada na maioria dos casos (quadro 1), exceto no município B, o de menor disponibilidade de serviços. Uma usuária de UBS tradicional, cuja coleta foi realizada em 2015, só recebeu busca ativa mais de 1 ano depois, quando teve que repetir o exame, e novamente apresentou resultado alterado, tendo realizado histerectomia total.

A avaliação dos resultados por meio de consulta na APS foi identificada na maioria das trajetórias, exceto para a metade das mulheres do município B e para algumas da zona rural, que apenas receberam o laudo do citopatológico alterado e data agendada para serviços da AE por funcionários da recepção da UBS ou ACS. Para estas mulheres, em nenhum momento foi fornecida qualquer informação sobre o diagnóstico por profissionais da APS e algumas delas, mesmo após encaminhamento à $\mathrm{AE}$, ainda não tinham conhecimento do seu problema:

Porque esse exame meu, eu acho assim, porque eu não entendo muito dessas coisas, já eles entende né? Entáo quando esse exame chegou, eu acho que antes de marcar, eles devia ter dado um jeito pra conversar comigo e me explicar direitinho o que que tava acontecendo né? (E16SFRA).

O ACS esteve muito presente na busca ativa de mulheres com resultado alterado, na entrega de marcaçóes para $\mathrm{AE}$ e orientaçóes sobre o fluxo na rede, sobretudo na zona rural. Todas as usuárias afirmaram conhecer este profissional, e onde a microárea era descoberta (três casos do município A), esta ação ficava a cargo de outro ACS ou de funcionários da recepção. No município sede, houve predominância da realização de açôes de CCCU por enfermeiros, responsáveis pelo encaminhamento para $\mathrm{AE}$ e seguimento. Nos outros municípios, tais profissionais geralmente só realizaram a coleta.

A comunicação entre profissional e usuária, quando ocorreu, no momento da avaliação do resultado do citopatológico, por muitas vezes foi frágil, com utilização 
de termos que subestimavam o problema ("alteraçãozinha", "manchinha” ou “nodulozinho”) ou o agravavam ("câncer”), gerando dúvidas, desespero e preocupação:

[...] não gostei muito da mulher [enfermeira] que veio trazer a notícia dizendo que eu estava com câncer [...] eu estava sozinha na minha casa, não tinha ninguém mais eu. Eu tomei um baita susto, minha pressão subiu. Chorei desesperadamente [...] a moça que veio aqui me dar essa notícia horrível (E7UBSUA).

Todas as usuárias foram encaminhadas para a AE pelas equipes de APS. Raras relataram recebimento de relatório de referência a ser entregue ao especialista. A marcação foi realizada pela APS para a maior parte das mulheres, embora seis tenham agendado na Central de Marcação de Consultas (CMC) e uma diretamente no serviço especializado.

O quadro 1 sintetiza a trajetória assistencial das mulheres nas açôes de CCCU que fazem parte do escopo da APS. Cores suaves e fortes se contrastam no mesmo percurso, indicando trânsito mais livre e pontos de fluxo lento na busca pelo cuidado.

Quadro 1. Trajetórias assistenciais de mulheres com lesão precursora do câncer de colo do útero em unidades de APS, Bahia, 2018

\begin{tabular}{|c|c|c|c|c|c|c|c|c|c|c|c|}
\hline Usuária & 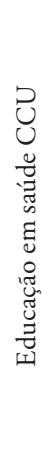 & 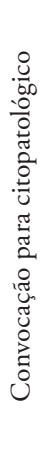 & 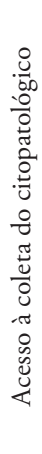 & 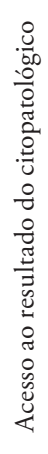 & 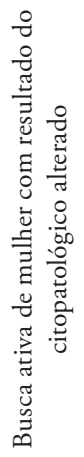 & 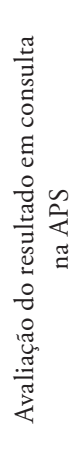 & 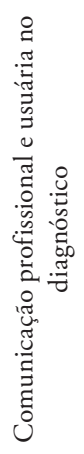 & 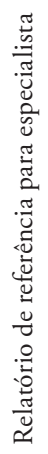 & 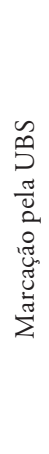 & 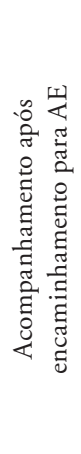 & 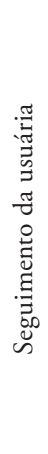 \\
\hline E1SFUB & & & & & & & & & & & \\
\hline E2SFUB & & & & & & & & & & & \\
\hline E3SFUB & & & & & & & & & & & $\mathrm{X}$ \\
\hline E4SFUB & & & & & & & & & & & $\mathrm{X}$ \\
\hline E5UBSUA & & & & & & & & & & & $\mathrm{X}$ \\
\hline E6UBSUA & & & & & & & & & & & \\
\hline E7UBSUA & & & & & & & & & & & $\mathrm{X}$ \\
\hline
\end{tabular}




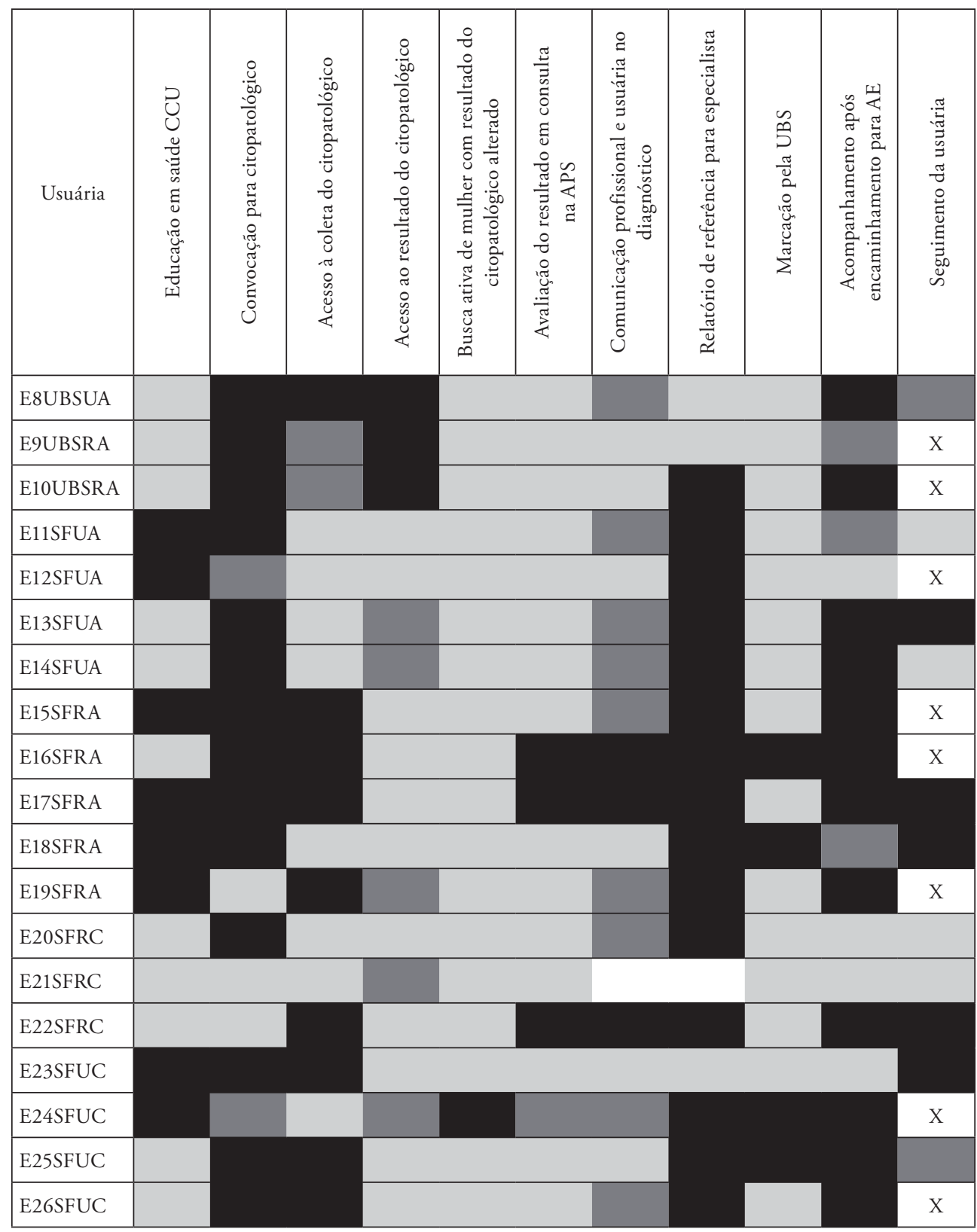

Fonte: elaboração própria, a partir das entrevistas.

Legenda: Cinza claro: facilidade de percurso; Cinza escuro: presença de barreiras no percurso; Preto: interrupção do percurso pela rede pública de saúde; X: usuária não se encontra nesta fase. 


\section{Longitudinalidade e coordenação do cuidado pela APS nas açóes de CCCU: "me encaminhou pro tratamento. Só foi até aî"}

Na maior parte das trajetórias náo foi identificado profissional de referência na APS que tenha coordenado o cuidado na rede. Houve casos em que mesmo quando as mulheres retornaram à UBS com outro objetivo, o seguimento não foi abordado. As poucas usuárias que retornaram após encaminhamento para a $\mathrm{AE}$ (sete dos municípios A e C) geralmente foi por iniciativa própria, seja para marcação de consultas/exames especializados e/ou avaliação de exames e novos encaminhamentos:

E me encaminhou pro tratamento. Só foi até aí. Agora, daí pra cá também, ninguém me procurou pra saber se eu fiz a cirurgia [...] não sabe se eu fiz cirurgia, nem se eu não fiz, nem como que tá minha saúde. Não tem acompanhamento, não tem [...] Porque, se a gente foi encaminhado daqui pra fazer o tratamento, deveria ter uma pessoa pra tá sabendo como que a gente tá né? Se a gente tá precisando de mais algum tratamento, alguma coisa (E10UBSRA).

Apenas três mulheres do município C (de menor porte) e uma do A (sede da regiáo), relataram busca ativa do ACS após início do tratamento. No caso do município sede, mesmo em área descoberta foi mencionada mobilização de outro ACS:

Aqui é ótimo, aqui o que eu perguntar, até um dedinho que tiver doente, Dália [enfermeira] me explica [...] ela manda Hortência [ACS] ou uma das menina vim aqui. Cadê, se eu sumir do posto [...] ela manda procurar saber como é que eu tô. [...] Ela nunca deixa de perguntar (E12SFUA).

Quase todas entrevistadas do município B (três de quatro) referiram busca tardia pela equipe de APS (7 meses a 1 ano e 3 meses após encaminhamento para AE), que ocorreu no mesmo período para todas as usuárias. Uma delas já havia finalizado tratamento há 8 meses.

Em quatro trajetórias (duas no município $\mathrm{C}$ e duas no A), profissionais da APS (enfermeiras e médicas) estabeleceram comunicação com a Central de Marcação de Consultas, por meio de relatório ou telefone, a fim de agilizar o acesso das usuárias à $\mathrm{AE}$.

Não havia registros de informações clínicas sobre qualquer ação de CCCU nos prontuários da maior parte das usuárias de UBS tradicional (quatro de seis) no município A. Ocorreu também em UBS tradicional dificuldade de acesso ao prontuário (necessidade do número de registro que somente a usuária dispunha), sendo este separado por especialidades (clínico, ginecologia e pré-natal), mesmo 
sendo da mesma usuária. Também identificou-se caso de três prontuários da mesma mulher, localizados em arquivos distintos.

Foi constatada interrupção de duas trajetórias no município A. Uma usuária de USF rural desistiu de fazer a colposcopia remarcada por sangramento apresentado na tentativa anterior. Outra usuária de UBS tradicional urbana não quis realizar biópsia, pois desejava retirar o útero sem fazer este exame. Mesmo decorridos 7 meses da remarcação da colposcopia para a primeira e 1 ano da coleta do citopatológico para a segunda, ambas náo haviam sido buscadas pela APS para acompanhamento e oferta de orientaçóes quanto ao tratamento. A entrevistada da zona rural não tinha nenhuma ideia sobre a gravidade de seu problema de saúde:

Aí ficou por isso mesmo, então eu acho que se fosse uma doença, alguma coisa assim, eles tinha que tá mais ali 'Não, você tem que fazer esse exame porque esse exame seu aqui é isso e aquilo ali'. Então, então eu acho assim que não tão aí se você fez ou se você deixou de fazer. Então eu acho que se preocupa com você, é você mesma (E16SFRA).

Uma usuária de USF urbana do município A que não foi acompanhada pela APS teve o percurso pela rede de referência descontinuado em função de preenchimento incorreto da solicitação do anatomopatológico. Neste caso, o laboratório não aceitou o material e orientou que a usuária retornasse ao médico solicitante, o que fez por diversas vezes sem sucesso, até descartar o material.

Para as mulheres que já estavam na fase do seguimento (14 de 26), ou seja, precisavam repetir o citopatológico após diagnóstico ou tratamento, a equipe de APS não havia realizado busca ativa até o momento de realização das entrevistas. Nenhuma usuária relatou o recebimento da contrarreferência. Nesta etapa, duas entrevistadas ainda não haviam conseguido realizar o citopatológico, mesmo após diversas tentativas. No caso de uma usuária do município C, o de menor porte, o procedimento foi desmarcado devido à liminar da Justiça Federal (27/09/17), que resultou na proibição da realização de coleta do exame por enfermeiros.

Ademais, chamou a atenção o fato de o citopatológico de seguimento de três usuárias (dos três municípios) ter sido efetuado ou marcado no setor privado, pelo receio quanto à demora do resultado quando realizado na APS. Também foi identificado em duas trajetórias do município A realização no serviço público especializado responsável pela confirmação diagnóstica. 


\section{Discussão}

As trajetórias assistenciais das usuárias com lesão precursora do câncer do colo uterino revelaram barreiras de acesso e organização do processo de trabalho nas açôes gerais da APS e também para as de controle do CCU, mais acentuadas no município com menor disponibilidade de recursos assistenciais e no meio rural, mesmo quando no município sede. Ademais, diferenças também foram verificadas entre as modalidades de APS, com maiores dificuldades nas UBS tradicionais, resultados também encontrados em outros estudos (FLÔR et al., 2017).

A APS foi apontada como espaço indispensável para busca regular de diversos serviços e açóes, o que sugere sua centralidade para os cuidados em saúde das entrevistadas. Contudo, ainda que observada alta cobertura de APS para os municípios do interior da região, para acessá-la, as usuárias enfrentam filas e número restrito de vagas para consultas médicas. Mesmo no município sede, na zona rural, o acesso é um ponto crítico, com a APS operando de forma esporádica, o que resultou em peregrinação na busca por cuidados primários, resultados semelhantes aos de Carvalho et al. (2016).

Os achados demonstram a necessidade de organização diferenciada da APS para atender territórios com grande dispersão territorial e, em geral, com população em situação de maior vulnerabilidade. Estudo de Fausto et al. (2017) também constata dificuldades no acesso e deficiências no acompanhamento de usuários com condição crônica pela APS, mais intensas no meio rural. A busca por cuidados em áreas rurais envolve garantia de transporte, que se constitui importante barreira financeira de acesso aos serviços de saúde.

A falta de atendimento às urgências na APS decorreu em idas e vindas entre hospitais, UPAs e UBS, com informaçōes descoordenadas entre os serviços. Dificuldade de acesso à $\mathrm{AE}$, gastos com transporte e peregrinação na busca por cuidados primários aumentaram a percepção de baixa resolutividade da APS e colabora para o desprestígio da APS por parte dos usuários (BEZERRA; CARVALHO, 2013).

Para além da questão da rotatividade de médicos como apontado em outro estudo (SANTOS; GIOVANELLA, 2016), chama a atenção a persistente substituição de diversos profissionais das equipes de APS nos municípios do interior, após mudança da gestão municipal, situação que se repete eleição após eleição (ALMEIDA et al., 
2016), e que incorre em quebra de vínculo e baixa adesão. O abastecimento irregular de medicamentos, também evidenciado em outros estudos (BOUSQUAT et al., 2017; FAUSTO et al., 2017), foi marcante nas trajetórias, resultando em mais gastos diretos.

Avaliações positivas quanto ao atendimento prestado pela APS, sobretudo na modalidade ESF, estiveram presentes. Este achado confirma a relevância da APS para as usuárias, como ponto de atenção indispensável na busca por cuidados (SOUZA et al., 2014). Muitas entrevistadas relacionaram a satisfação ao acolhimento e possibilidade de diálogo com os profissionais. Achados de Almeida, Giovanella e Nunan (2012) também indicaram a atenção dispensada pelos profissionais como o elemento mais valorizado na ESF.

Em relação ao desenvolvimento das ações de CCCU, a APS apresentou-se frágil e incompleta. Em todos os contextos, a busca ativa para realização do citopatológico foi praticamente inexistente. Houve escassa participação em atividades educativas, ainda mais restrita na zona rural. As mulheres apresentaram conhecimento insuficiente em relação ao agravo, o que pode ter se refletido na busca pelo citopatológico mediante apresentação de sinais e sintomas. $\mathrm{O}$ acesso às açóes de promoção e de prevenção secundária não foi facilitado às mulheres residentes em áreas rurais, mesmo diante das marcadas vulnerabilidades. Maiores tempos de espera entre a coleta e resultado do citopatológico foram encontrados nos municípios do interior, o que converge com outros estudos (LOFEGO; SILVEIRA, 2013).

Apesar de observados poucos casos de convocação para realização do citopatológico, iniciativas de busca ativa pela APS merecem destaque. Isso indica que, quando observada disposição para mudanças no processo de trabalho e comprometimento com o cuidado produzido, conferindo centralidade ao usuário, há possibilidade de melhorias, com repercussões positivas na vida dos sujeitos (MERHY, 2013).

Precário acolhimento e preocupante tecnicismo no momento da coleta em UBS tradicionais, bem como a presença de estudantes foram fatores que podem obstaculizar a adesão ao rastreamento. Ressalta-se a importância da integração ensino-serviço e sua necessidade, como ilustrado no desenvolvimento de atividades educativas por acadêmicos, entretanto, respeitando-se o desejo e a individualidade das usuárias.

Falta de avaliação do laudo, em algumas situações, teve consequências negativas para o seguimento do cuidado. Mesmo nos casos em que houve consulta, a comunicação usuária-profissional na APS foi limitada, acarretando incerteza quanto 
ao diagnóstico e insegurança no percurso terapêutico, alijando-as da participação em seu processo de coordenação do cuidado, do qual deveria ser uma das protagonistas (MCDONALD et al., 2014).

Embora o encaminhamento para a AE tenha sido realizado desde a APS, poucas usuárias referiram recebimento de referência, o que denota fragilidade na comunicação interprofissional entre os níveis de atenção (BOUSQUAT et al., 2017; SILVA et al., 2016). Após encaminhamento à AE, a APS perdeu a direção sobre as trajetórias assistenciais, que indicaram um conjunto de deficiências no seguimento pela APS: infrequentes casos de busca ativa e/ou consultas após encaminhamento, inexistência de registros imprescindíveis ao acompanhamento, falta de registros nos prontuários na UBS tradicional, ausência de busca e dificuldades para realização do citopatológico de seguimento e falta de identificação do profissional de referência na APS.

Faz-se necessário ressaltar o fundamental papel dos ACS nas trajetórias assistenciais, assim como constatado por outros autores (ALELUIA et al., 2017). Para usuárias de zona rural, este profissional, muitas vezes, foi o principal contato na APS. À potencialização do trabalho do ACS, soma-se a necessidade de aumento do escopo de práticas dos enfermeiros, não apenas nas ações de CCCU, mas na clínica e na coordenação das trajetórias assistenciais (TOSO; FILIPPON; GIOVANELLA, 2016).

Muitos percursos revelaram problemas que poderiam ser resolvidos ou atenuados se a coordenaçáo do cuidado fosse bem desenvolvida pela APS. A interrupção de trajetórias por falta de orientação ilustra essa afirmativa. Todavia, é importante destacar que nos casos em que o seguimento foi realizado houve grande valorizaçáo por parte das usuárias, que se sentiam "cuidadas".

\section{Conclusão}

Em síntese, as trajetórias assistenciais desvelaram fragilidades no acesso e organização das açôes gerais e de controle do CCU pela APS, apontando desigualdades entre os municípios, entre área rural e urbana e ainda entre as modalidades de APS. De modo igual entre os municípios da regiáo, características de uma APS seletiva foram evidenciadas pela restrição da assistência farmacêutica, do escopo da prática da enfermagem, ausência de atividades educativas e importantes barreiras de acesso, além da burocratização na oferta do citopatológico. Ficou evidente a desarticulação das açôes realizadas pela própria APS, ou seja, o cuidado ainda quando ofertado 
pelo mesmo nível de atenção também foi fragmentado, evidenciando deficiências da integração horizontal, para além dos já reconhecidos problemas de acesso e coordenação aos demais níveis.

As barreiras foram mais acentuadas para usuárias da área rural, o que pode ampliar as desigualdades. Mulheres adscritas à UBS tradicionais também enfrentaram maiores dificuldades. Isto posto, e com base na inequívoca necessidade dos serviços e açôes da APS apontada pelas usuárias, não se trata de deixar de ser estratégica, principalmente em sua modalidade ESF, mas de reconhecer a incompletude e envidar esforços e recursos para melhoria de sua qualidade.

Embora o usuário, ator privilegiado neste estudo, deva ser o centro dos sistemas de saúde, a percepção de gestores e profissionais também é fundamental para compreensão do acesso e organização da APS, além de análises que considerem outros aspectos essenciais para qualidade do cuidado. Ademais, fornece elementos para realizaçáo de estudos com utilização de condiçóes traçadoras de maior prevalência, tendo como cenário o imprescindível fortalecimento dos desenhos regionais no SUS. ${ }^{1}$

\section{Agradecimentos}

Ao CNPq, pela bolsa do Programa de Pós-Doutorado Júnior (Processo 150036/2017-5), concedido à segunda autora.

\section{Referências}

ALELUIA, I. R. S. et al. Coordenação do cuidado na atenção primária à saúde: estudo avaliativo em município sede de macrorregião do nordeste brasileiro. Ciênc. saúde coletiva. Rio de Janeiro, v. 22, n. 6, p. 1845-1856, jun. 2017.

ALMEIDA, P. F. et al. Integração assistencial em região de saúde: paradoxo entre necessidades regionais e interesses locais. Saúde soc. São Paulo, v. 25, n. 2, p. 320-335, jun. 2016.

ALMEIDA, P. F.; FAUSTO, M. C. R.; GIOVANELLA, L. Fortalecimento da atenção primária à saúde: estratégia para potencializar a coordenação dos cuidados. Rev Panam Salud Publica, v. 29, n. 2, p. 84-95, fev. 2011.

ALMEIDA, P. F.; GIOVANELLA, L.; NUNAN, B. A. Coordenação dos cuidados em saúde pela atenção primária à saúde e suas implicaçōes para a satisfação dos usuários. Saúde Debate. Rio de Janeiro, v. 36, n. 94, p. 375-391, set. 2012. 
ALMEIDA, P. F.; SANTOS, A. M. Atenção Primária à Saúde: coordenadora do cuidado em redes regionalizadas? Rev. Saúde Pública. São Paulo, v. 50, 80, 2016.

AQUINO, R.; OLIVEIRA, N. F.; BARRETO, M. L. Impact of the Family Health Program on infant mortality in Brazilian municipalities. Am J Public Health. 2009.

ARANTES, L. J.; SHIMIZU, H. E.; MERCHAN-HAMANN, E. Contribuiçóes e desafios da Estratégia Saúde da Família na Atenção Primária à Saúde no Brasil: revisão da literatura. Ciênc. saúde coletiva. Rio de Janeiro, v. 21, n. 5, p. 1499-1510, maio 2016.

BAHIA. SUVISA - Superintendência de Vigilância e Proteção à Saúde. DIS - Diretoria de Informação em Saúde. Salvador: SESAB, 2012. Disponível em: <http://www3.saude.ba.gov.br/ cgi/tabcgi.exe?TabNet/populacao/popresid.def>. Acesso em 15 abr. 2018.

BEZERRA, R. S.; CARVALHO, E. L. Profissionais de saúde e dispositivos de mediação na atenção Básica. In: PINHEIRO, R.; MARTINS, P. H. (Org.). Usuários, redes sociais, mediaçóes e integralidade em saúde. Rio de Janeiro: UERJ/IMS/LAPPIS, 2013, p. 149-160.

BOERMA, W. G. W. Coordenação e integração em atenção primária europeia. In: SALTMAN, R. B.; RICO, A.; BOERMA, W. G. W. (Org.). Atenção Primária conduzindo as redes de atenção à saúde: reforma organizacional na atenção primária europeia. Berkshire: Open University Press, 2010, p. 25-47.

BOUSQUAT, A. et al. Atenção primária à saúde e coordenação do cuidado nas regiōes de saúde: perspectiva de gestores e usuários. Ciênc. saúde coletiva. Rio de Janeiro, v. 22, n. 4, p. 1141-1154, abr. 2017 .

BRASIL. Ministério da Saúde. Departamento de Atenção Básica. Histórico de Cobertura da Saúde da Família. Fev. 2018. Disponível em: <http://dab.saude.gov.br/portaldab/historico_ cobertura_sf.php >. Acesso em: 18 mar. 2018.

- Ministério da Saúde. Secretaria de Atenção à Saúde. Departamento de Atenção Básica. Controle dos cânceres do colo do útero e da mama. In: Cadernos de Atenção Básica. 2. ed. Brasília: Editora do Ministério da Saúde, 2013. 124 p.

BRITO-SILVA, K. et al. Integralidade no cuidado ao câncer do colo do útero: avaliação do acesso. Rev. Saúde Pública. São Paulo, v. 48, n. 2, p. 240-248, abr. 2014.

CARVALHO, I. L. N. et al. Exame citopatológico: compreensão de mulheres rurais acerca da finalidade e do acesso. Rev. RENE, v. 17, n. 2, p. 610-617, set.-out. 2016.

CECILIO, L. C. O. et al. A Atenção Básica à Saúde e a construção das redes temáticas de saúde: qual pode ser o seu papel?. Ciênc. saúde coletiva. Rio de Janeiro, v. 17, n. 11, p. 2893-2902, nov. 2012.

DATASUS. Informações de Saúde. Rede Assistencial. CNES-Estabelecimento por tipo. Abr. 2018. Disponível em <http://tabnet.datasus.gov.br/cgi/tabcgi.exe?cnes/cnv/estabba.def >. Acesso em: 9 maio 2018. 
DOURADO, I. et al. Trends in primary health care-sensitive conditions in Brazil: the role of the Family Health Program (Project ICSAP-Brazil). Med Care. 2011.

FAUSTO, M. C. R. et al. Itinerários terapêuticos de pacientes com acidente vascular encefálico: fragmentação do cuidado em uma rede regionalizada de saúde. Rev. Bras. Saúde Mater. Infant. Recife, v. 17, supl. 1, p. S63-S72, 2017.

FLÔR, C. R. et al. Primary health care as assessed by health professionals: comparison of the traditional model versus the Family Health Strategy. Rev. bras. epidemiol. São Paulo, v. 20, n. 4, p. 714-726, dez. 2017.

GERHARDT, T. E.; BURRILLE, A.; MÜLLER, T. L. Estado da arte da produção científica sobre itinerários terapêuticos no contexto brasileiro. In: GERHARDT, T. E. et al. (Org.). Itinerários Terapêuticos: integralidade no cuidado, avaliação e formação em saúde. Rio de Janeiro: CEPESC:ABRASCO, 2016, p. 27-97.

GIRIANELLI, V. R.; GAMARRA, C. J.; AZEVEDO E SILVA, G. Os grandes contrastes na mortalidade por câncer do colo uterino e de mama no Brasil. Rev. Saúde Pública. São Paulo, v. 48, n. 3, p. 459-467, jun. 2014.

INSTITUTO BRASILEIRO DE GEOGRAFIA E ESTATÍSTICA. Rio de Janeiro: IBGE. 2010. Disponível em: <http://www.cidades.ibge.gov.br/xtras/perfil.php?lang=\&codmun=2933 30\&search=bahia|vitoria-da-conquista>. Acesso em: 29 mar. 2018.

INCA. Atlas On-line de Mortalidade. Disponível em: <https://mortalidade.inca.gov.br/ MortalidadeWeb/pages/Modelo04/consultar.xhtml\#panelResultado>. Acesso em 12 abr. 2018.

- Coordenação de Prevenção e Vigilância. Estimativa 2018: incidência de câncer no Brasil. Rio de Janeiro: INCA, 2017. 128 p.

LOFEGO, J.; SILVEIRA, R. Três Marias e seus itinerários terapêuticos: mediadores na busca de cuidado para o câncer de colo do útero em uma Regional de Saúde no Estado do Acre. In: PINHEIRO, R.; MARTINS, P. H. (Org.). Usuários, redes sociais, mediações e integralidade em saúde. Rio de Janeiro: UERJ:IMS:LAPPIS, 2013, p. 123-136.

MALTA, D. C. et al. A Cobertura da Estratégia de Saúde da Família (ESF) no Brasil, segundo a Pesquisa Nacional de Saúde, 2013. Ciênc. saúde coletiva. Rio de Janeiro, v. 21, n. 2, p. 327-338, fev. 2016.

McDONALD, K. M. et al. Care Coordination Atlas Version 4. Rockville: AHRQ Publication. Jun. 2014.

MERHY, E. E. Em busca do tempo perdido: a micropolítica do trabalho vivo em saúde. In: FRANCO, T. B.; MERHY, E. E. (Org.). Trabalho, produção do cuidado e subjetividade em saúde: textos reunidos. São Paulo: Hucitec, 2013, p. 19-67. 
OLIVEIRA, I. S. B. et al. Açóes das equipes de saúde da família na prevenção e controle do câncer de colo de útero. Ciênc. cuid. Saúde. São Paulo, v. 9, n. 2, p. 220-227, jun. 2010.

PINHEIRO, R.; SILVA JÚNIOR, A. G. A centralidade do usuário na avaliação em saúde: outras abordagens. In: PINHEIRO, R., MARTINS, P. H. (Org.). Avaliação em saúde na perspectiva do usuário: abordagem multicêntrica. Rio de Janeiro: CEPESC:IMS-UERJ; 2011, p. 37-51.

RODRIGUES, A. D.; BUSTAMANTE-TEIXEIRA, M. T. Mortalidade por câncer de mama e câncer de colo do útero em município de porte médio da Região Sudeste do Brasil, 1980-2006. Cad. Saúde Pública. Rio de Janeiro, v. 27, n. 2, p. 241-248, fev. 2011.

SANTOS, A. M.; GIOVANELLA, L. Estratégia Saúde da Família na coordenação do cuidado em região de saúde na Bahia. Saúde debate. Rio de Janeiro, v. 40, n. 108, p. 48-63, mar. 2016.

SILVA, M. R. F. et al. Continuidade Assistencial a mulheres com câncer de colo de útero em redes de atenção à saúde: estudo de caso, Pernambuco. Saúde debate. Rio de Janeiro, v. 40, n. 110, p. 107-119, set. 2016.

SILVA, V. M. N. et al. Trajetória assistencial em Piraí: uma prática avaliativa amistosa à integralidade. In: PINHEIRO, R.; SILVA JR., A. G.; MATTOS, R. A. (Org.). Atenção básica e integralidade: contribuiçôes para estudos de práticas avaliativas em saúde. Rio de Janeiro: CEPESC-IMS:UERJ-ABRASCO; 2011, p. 225-232.

SOUZA, A. L. M. et al. Indicaçóes sobre a contribuição da Atenção Básica na construção de redes de atenção à saúde: entre o desejo e a realidade. In: CECÍLIO, L. C. O.; CARAPINHEIRO, G.; ANDREAZZA, R. (Org.). Os mapas do cuidado: o agir leigo na saúde. São Paulo: Hucitec: Fapesp, 2014, p. 65-88.

TANAKA, O. Y.; ESPIRITO SANTO, A. C. G. Avaliação da qualidade da atenção básica utilizando a doença respiratória da infância como traçador, em um distrito sanitário do município de São Paulo. Rev. Bras. Saúde Mater. Infant. Recife, v. 8, n. 3, p. 325-332, set. 2008. TOMASI, E. et al. Estrutura e processo de trabalho na prevenção do câncer de colo de útero na Atenção Básica à Saúde no Brasil: Programa de Melhoria do Acesso e da Qualidade - PMAQ. Rev. Bras. Saúde Mater. Infant. Recife, v. 15, n. 2, p. 171-180, jun. 2015.

TOSO, B. R. G. O.; FILIPPON, J.; GIOVANELLA, L. Atuação do enfermeiro na Atenção Primária no Serviço Nacional de Saúde da Inglaterra. Rev. Bras. Enferm. Brasília, v. 69, n. 1, p. 182-191, fev. 2016.

\section{Nota}

${ }^{1}$ J. R. Galvão e P. F. de Almeida participaram da concepção da pesquisa, análise dos dados e redação do artigo. A. M. dos Santos e N. F. S. Fernandes participaram da redação e revisão da versão final do artigo. 


\section{Abstract}

Care trajectories of users with precursor lesions of cervical cancer by primary health care in a health region: free transit, length and stop points

The article aims to evaluate the access and organization of Primary Health Care (PHC) actions using cervical cancer (CCU) as a tracer event. Assistance trajectories of women with diagnosis of high grade cervical lesion were constructed, from Basic Health Units and Family Health Units, urban and rural areas, in the interior municipalities and at the headquarters of a health region of the Bahia. Women indicate difficulty accessing medical consultations in PHC, especially in rural areas. In addition to the obstacles to cytopathological scheduling, most patients report not being called to accomplish it and do not participate in educational activities on the issue. The control actions of the CCU in PHC are restricted to cytopathology, evaluation of the outcome and referral to specialized care, without follow-up care and with failures in professional-user communication. Barriers to access to PHC in general and to CCU control related to the scope of actions were identified, mainly in the units located in the municipality with less availability of services, in the rural area and in the traditional Basic Health Units.

> Keywords: Primary Health Care; comprehensive health care; uterine cervical neoplasms. 